The effects of voluntary front-of-pack nutrition labels on volume shares of products the case of the Dutch choices

Smed, Sinne; Edenbrandt, Anna K.; Jansen, Léon

Published in:

Public Health Nutrition

DOI:

$10.1017 / \mathrm{S} 1368980019001423$

Publication date:

2019

Document version

Publisher's PDF, also known as Version of record

Citation for published version (APA):

Smed, S., Edenbrandt, A. K., \& Jansen, L. (2019). The effects of voluntary front-of-pack nutrition labels on volume shares of products: the case of the Dutch choices. Public Health Nutrition, 22(15), 2879-2890.

https://doi.org/10.1017/S1368980019001423 


\title{
The effects of voluntary front-of-pack nutrition labels on volume shares of products: the case of the Dutch Choices
}

\author{
Sinne Smed ${ }^{1, *}$, Anna K Edenbrandt ${ }^{2}$ and Léon Jansen ${ }^{3}$ \\ 'Department of Food and Resource Economics, University of Copenhagen, Rolighedsvej 25, DK-1958 Frederiksberg C, \\ Denmark: ${ }^{2}$ Department of Economics, Swedish University of Agricultural Science, Uppsala, Sweden: ${ }^{3}$ Schuttelaar \& \\ Partners, Wageningen, The Netherlands
}

Submitted 30 April 2018: Final revision received 14 March 2019: Accepted 27 March 2019: First published online 24 June 2019

\begin{abstract}
Objective: The study examines the impact of a front-of-pack label (Dutch Choices) on household purchase patterns.

Design: Change in households' volume share of products eligible for the label (treatment group) is estimated as a function of changes in the market share of products displaying the label (treatment), while controlling for other relevant factors. Setting: Home-scan data for five food categories, subdivided into eighteen food groups, for households participating in a Dutch consumer panel. The data are from the period 2005 to 2009, which includes the date of the introduction of the Choices label.

Participants: Between 831 and 7216 households from all over the Netherlands.

Results: An increase in the market share of products displaying the label led to an increase in the volume share purchased of products eligible for the label for dairy products, yoghurts and for sauces. For some of the products, the partial effect is considerable (e.g. a 10 percentage point (pp) increase in the share of products displaying the label is associated with a 11.5 and $14.0 \mathrm{pp}$ increase in the volume share of eligible products for chocolate milk and quark, respectively).

Conclusions: The results suggest a positive effect from the presence of the Choices label on the volume share of eligible products purchased. Provided that eligible products are healthier than non-eligible products, the Choices label is a good guide for consumers in order to help them make healthier food choices. The positive effect is found mainly in food groups with a mix of both healthy and unhealthy food products.
\end{abstract}

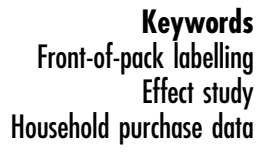

An unhealthy diet is one of the most important behavioural risk factors for lifestyle-related diseases, next to physical inactivity, tobacco use and excessive use of alcohol ${ }^{(1)}$. The prevalence of obesity is rising globally, leading to deaths related to type 2 diabetes, cancer and $\mathrm{CVD}^{(2,3)}$, the costs of which are projected to be between 2 and $6 \%$ of the health-care budget in various countries ${ }^{(4)}$. Information provision to consumers in the form of campaigns, education or food labelling is increasingly considered a crucial component of comprehensive strategies to tackle these problems with increased lifestyle-related diagnosis ${ }^{(5,6)}$. One implication of this is that back-of-pack nutrition labelling is now mandatory in many countries ${ }^{(7)}$ including the USA and the EU, where the nutritional composition must be displayed in nutrition content tables of a certain format ${ }^{(8)}$. However, in US-based studies, these nutrition content tables have been shown to have a limited or insignificant effect on consumption and dietary quality ${ }^{(9-11)}$. The limited effect of nutrition content tables might be because consumers find them difficult to read and interpret, as it requires time, effort and prior knowledge of nutrition ${ }^{(12-14)}$. Furthermore, the use and understanding of nutrition content tables varies between population groups and is positively correlated with healthier eating habits, nutrition knowledge and higher education $^{(12,13)}$. In response to the diverging use and understanding of nutrition content tables, a number of private and public initiatives have developed front-of-pack (FoP) nutrition labelling schemes ${ }^{(8)}$ in an attempt to make the information easier to access and absorb. Furthermore, the WHO promotes FoP nutrition labelling as part of a comprehensive policy response to obesity and diet-related non-communicable diseases ${ }^{(15)}$. FoP nutrition labelling schemes are found to be of more interest and more easily understood than nutrition content tables, especially by low-educated 


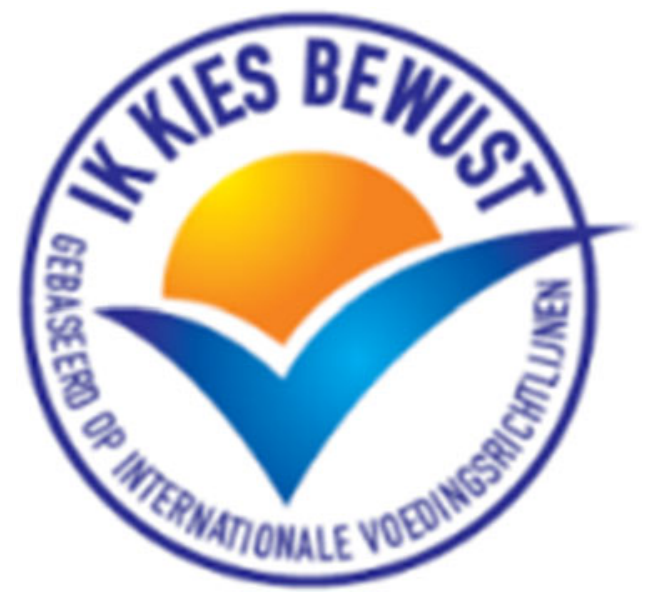

Fig. 1 The Dutch Choices label

households ${ }^{(13,16,17)}$. A variety of FoP nutrition labelling systems with varying levels of detail exist, but they commonly aim to: (i) assist consumers in making healthier food choices; and (ii) stimulate food manufacturers to produce healthier products ${ }^{(16,15)}$. Voluntary FoP labelling has been adopted in many countries, including the Scandinavian countries (Keyhole), the Netherlands (Dutch Choices label), the Czech Republic (Czech Choices label), Finland (Heart label), the UK (Multiple Traffic Light), New Zealand and Australia (Health Star Rating System and the Tick) and Ecuador (Traffic light) ${ }^{(18-21)}$. The objective of the present study is to investigate whether displaying the Dutch Choices label affects the volume share of these products purchased by consumers. To enable us to explore whether displaying the label has any effects, consumer panel purchase data for a 4-year period are used, while several different food groups are analysed both before and after they started to display the label. Despite the increasing availability of FoP labelling schemes, there is only a limited amount of research that analyses the effect of these labels based on real market purchase data ${ }^{(15,17)}$.

Studies evaluating the effects of FoP labelling reveal that there is widespread interest in having nutrition information on food packages and that consumers like the idea of simplified FoP information ${ }^{(12-14,22)}$. In survey-based studies, consumers state that they have preferences for labelled products $^{(23)}$ and that labels improve the perceived healthiness of the labelled product ${ }^{(24)}$. Furthermore, FoP labels are shown to improve consumers' ability to find and understand nutritional information ${ }^{(25)}$. A meta-analysis based on laboratory and field experimental studies shows that both FoP and back-of-pack food labelling may influence consumers to choose healthier food products. This holds for labels with different levels of detail, ranging from the most detailed Guideline Daily Amount labels to traffic light- and logo-based labels ${ }^{(26)}$. Few studies use market data in the form of retail sales data or consumer panel purchase data to evaluate the effect of the implementation of FoP labelling in a real-life setting ${ }^{(15)}$. Studies using supermarket sales data found a decrease in unhealthy food consumption after the introduction of a three-star nutrition label system in specific supermarkets in the USA ${ }^{(27,28)}$. A UK study based on scanner data at the aggregated level found that Guideline Daily Amount nutrition labels reduced the market share of unhealthy products ${ }^{(29)}$, while for a group of consumers a decrease in the likelihood of choosing some unhealthy alternatives compared with the healthiest option was shown. Finally, a study based on sales data in a supermarket environment found mixed effects from the introduction of a traffic light system in the $\mathrm{UK}^{(30)}$. Several authors suggest that insights regarding the actual use and purchases of nutrition-labelled products is an emerging need ${ }^{(16,31,32)}$. The sparse availability of studies that evaluate the effects of FoP labels using data from actual consumer behaviour is the motivation behind the present paper.

Two previous studies, which partly use the same data as the current study, have investigated which consumer types are most likely to purchase nutrition-labelled products ${ }^{(33)}$ and whether displaying the label on the packaging has an effect on consumer willingness to pay for the product ${ }^{(34)}$. The overall conclusion from these studies is that sociodemographic characteristics are relatively poor in explaining the probability of purchasing labelled products, and that for many products, displaying the Choices label had a positive effect on the willingness to pay. The current study contributes further knowledge about how displaying the Dutch Choices nutrition label affects the volume share of eligible products purchased within different food groups from different food categories. An important contribution of the study is the use of consumer panel purchase data. In the current study, a product is considered healthy if it is eligible to display the Choices label and did in fact display the Choices label at some point in the time period of the study. The implications of this assumption are discussed.

\section{Methods}

\section{The Dutch Choices label}

The Dutch Choices label, which is displayed in Fig. $1,{ }^{*}$ is a criteria-based labelling system that certifies whether a specific product is a healthy choice within the product category in question. It is, hence, a logo-type label that is displayed only on products that fulfil the requirements ${ }^{(15)}$. A healthy choice is defined based on the levels of SFA, added sugar, salt, dietary fibre and/or energy in the product with the criteria for the label being revised periodically. The actual criteria applied depend on the product category being considered. The Dutch Choices, the use of which is voluntary among producers, was implemented in 2006 by a multi-stakeholder board. Membership of the Choices

*In 2010, after our data period, two versions of the Choices label were introduced: green for genuinely healthy, and blue to indicate the healthier choice within a category of usually unhealthy foods. The figure here shows the original Choices logo as used before 2010. 
organization is necessary in order to be able to apply for permission to display the label, although the fee is marginal for producers and depends on the annual turnover of a company. On average, small companies pay about $€ 900$ per year. The fee increases incrementally until it reaches a maximum of $€ 100000$ for companies in the highest turnover class. A national agent ensures that the requirements have been fulfilled prior to certifying that the producer may display the label ${ }^{(35)}$.

\section{Variables}

To be able to investigate whether displaying the Choices label on a product causes households to purchase more of that product, we constructed a dummy variable $j \in$ $(0,1)$, taking the value $j=1$ for products that at some point got the Choices label (this is our treatment group) and $j=0$ for products that did not at any time during the data period get the label (this is our control group). The $j$ dummy is time-invariant, taking the value of 1 during the whole period if the specific type of product got the Choices label during the period of the study. In the remaining part of the paper, we refer to these as eligible $(j=1)$ and non-eligible $(j=0)$ products, respectively. We acknowledge that there may be products that did not apply for the Choices label throughout the period, even though they were eligible. Information about whether a product was eligible, regardless of whether it actually displayed the label during the data period, would have been preferable, but unfortunately this was not available.

The volume share of our treatment group products (i.e. products that at some point displayed the label) is called share_eligible, which was calculated for each individual household $i$ in each time period $t$ as:

$$
\text { share_eligible }_{i t}=\frac{\text { volume }_{i t, j=1}}{\sum_{j} \text { volume }_{i t, j}}
$$

We also constructed a dummy variable indicating whether a product within a product type actually displayed the label $(k=1)$ or not $(k=0)$. This dummy can vary over time, which implies that the product only takes the value $k=1$ on the date when it obtained the label and thereafter. After constructing the dummy, we aggregated over households and calculated the fraction of the eligible products that actually displayed the label. This variable share_display_label is, hence, similar for all households and represents the supply of products that displayed the label (i.e. this is our treatment variable):

$$
\text { share_display_label }_{t}=\frac{\sum_{i} \text { volume }_{i t, k=1}}{\sum_{i} \sum_{k} \text { volume }_{i t, k}}
$$

By estimating the effect of share_display_label on share_eligible, while controlling for other factors that can affect the purchase of products, we can see whether displaying the label on products (i.e. the treatment) increased the volume share of eligible products purchased for the individual households.

The share_display_label, which was constructed as an average over households, might be endogenous since the purchases of the individual household affect the overall average. This effect is, however, considered to be very small since the number of households was large and each individual household, therefore, contributed only a small fraction to the average. Still, as a sensitivity analysis, we also calculated the number of distinct products (based on the European Article Number, or EAN-code) that displayed the label at each point in time and used this as the main explanatory variable:

$$
n u m b \_d i s p l a y \_l a b e l_{t}=\sum \text { eancodes }_{t, k=1}
$$

This measure prevents the endogeneity from households affecting the overall market share. However, it does have a disadvantage since, in this approach, a product that constitutes only a minor share of the market will count equally as a product that has a large market share. This implies that when we use the number of products displaying the label as explanatory variable, the size of the treatment will not be reflected in the estimation.

\section{Statistical analysis}

The explained variable, share_eligible, describes the volume share of products that at some point displayed the Choices label. This variable is restricted by the values 0 and 1 and can take any value in between. For example, households that purchased only eligible products have share_eligible $=1$. Households that did not purchase any products that were eligible for the label have share_eligible $=0$. Many households purchased a volume share somewhere in between. For models with explained variables that take this format, a two-sided censored Tobit model is suitable ${ }^{(36)}$ since it does not provide predictions outside the possible range (smaller shares than 0 or larger shares than 1). This model defines the explained variable in terms of an underlying latent variable $\left(y^{*}=\boldsymbol{X} \boldsymbol{\beta}+u\right)$, where $\boldsymbol{X}$ represents the explanatory variables in the analysis (e.g. product and household characteristics) and $\boldsymbol{\beta}$ is a vector of coefficients to be estimated. The underlying latent variable $y^{*}$ is not observed, but can be expressed in terms of the observed variable $y$ (i.e. share_eligible). The observed explained variable equals the latent variable when the latent variable is between 0 and 1 , while it equals 0 for values smaller than or equal to 0 and it equals 1 for values of 1 and above. This ensures that the probabilities for all outcomes lie between 0 and 1 . The two-sided Tobit model enables estimation of both the probability and the expected volume share of eligible products purchased (see equations (a1), (a2) and (a3) in the online supplementary material, Supplemental File A). Importantly, with this model specification, we can investigate whether the overall market share of products that displayed the Choices label 
Table 1 Description of explanatory variables in the model

\begin{tabular}{|c|c|}
\hline Share_display_label & Share of total volume purchased that consists of products that display the Choices label (av) \\
\hline Numb_display_label & Number of products that display the Choices label on packaging based on EAN-code level \\
\hline Share_organic & Share of total volume purchased that is organic \\
\hline Share_ownlabel & Share of total volume purchased that is own label \\
\hline Share super & Share of total volume that is purchased in supermarkets \\
\hline Share_discount & Share of total volume that is purchased in discount stores \\
\hline Share service & Share of total volume that is purchased in service and other types of store (base)t \\
\hline Rel_price & Relative average price of eligible products over products defined as not eligible (av)* \\
\hline$s_{m}$ & $\begin{array}{l}\text { Seasonality } \\
\text { (For estimations on months) Month dummies }(1=\text { if purchased in January, etc.) (av)* } \\
\text { (For estimation on quarters) Quarter dummies }\left(1=\text { if purchased in Q1, etc.) (av) }{ }^{\star}\right.\end{array}$ \\
\hline y06-y08 & Yearly dummies to account for preference-driven change over time $(a v)^{*}$ \\
\hline$s_{h}$ & Household characteristics \\
\hline Hh_size & Number of people in household \\
\hline Female & Gender dummy for person doing most housework and shopping $(1=$ female, $0=$ male $)$ \\
\hline Educ_low & Education dummy ( $1=$ person with highest education is low educated) (base) $\dagger$ \\
\hline Educ_mid & Education dummy ( $1=$ person with highest education is middle educated) \\
\hline Educ_high & Education dummy ( $1=$ person with highest education is high educated) \\
\hline City & District dummy ( $1=$ household living in one of the three big cities) (base) $\dagger$ \\
\hline West & District dummy ( $1=$ household living in the west) \\
\hline South & District dummy ( 1 = household living in the south) \\
\hline North & District dummy ( $1=$ household living in the north) \\
\hline East & District dummy ( $1=$ household living in the east) \\
\hline Single & Relationship dummy ( $1=$ household consists of one person) \\
\hline Inc_low & Income dummy $(1=$ net household income per month is $<€ 2100)$ (base) $\dagger$ \\
\hline Inc_mid & Income dummy $(1=$ net household income per month is $€ 2100-3500)$ \\
\hline Inc_high & Income dummy $(1=$ net household income per month is $>€ 3500)$ \\
\hline Age young & Age dummy ( $1=$ main shopper's age is $<35$ years) (base) $t$ \\
\hline Age_mid & Age dummy ( $1=$ main shopper's age is $35-54$ years $)$ \\
\hline Age_old & Age dummy ( $1=$ main shopper's age is $\geq 55$ years) \\
\hline
\end{tabular}

*(av) for average indicates that it is a variable that is common to all households

$t$ (base) indicates that this is used as the base level in the estimation.

on the packaging affected the volume share of eligible products purchased (share_eligible).

The non-linearity of the Tobit model implies that the partial effects (i.e. how changes in share_display_label affect share_eligible) depend on all explanatory variables in the model. This can be addressed by calculating the average partial effect (APE), which is obtained by calculating the partial effect for each of the households in the sample and then taking the average over all households (see equations (a4) and (a5) in Supplemental File A).

\section{Data and empirical specification}

The data used for the analysis are purchase data provided by the GfK Consumer Scan Panel in the Netherlands,* where members of the panel scan all their food purchases on a daily basis. The panel is representative of the population with respect to basic sociodemographic characteristics and covers households from the whole country. The purchase data provide information about the price and size of the product, store type, whether it is organic, and whether the product is a company brand or the store's own brand. The panel is unbalanced, which implies that the number of households in the data set varies over time. Data also include information about the labelling status as well as the month and year that the specific product started

*For more information about the GfK consumer panel, see https://www.gfk. $\mathrm{com} / \mathrm{nl} /$ over-gfl/overview. to display the Choices label. The data cover one year prior to the introduction of the label in 2006 and the following three years after the launch until the end of 2008. The panel structure of the data enables us to control whether the overall market share of products displaying the label on the packaging affects the volume share of eligible products purchased for individual households. This is similar to estimating the average treatment effects, where the treatment groups comprise products that are eligible for the Choices label and the control group comprises the remaining products within that food group. The treatment is the actual display of the label on the packaging. The model for the latent variable, estimated for each of the food groups, is:

$$
\begin{aligned}
y_{i t}^{*} & =\beta_{0}+\delta_{1} y 06+\delta_{2} y 07+\delta_{3} y 08+\sum_{m=1}^{11} \delta_{m} s_{m} \\
& +\beta_{1} \text { share_display_label }_{t}+\beta_{2} \text { share_organic }_{i t} \\
& +\beta_{3} \text { share_ownlabel }_{i t}+\beta_{4} \text { share_discount }_{i t} \\
& +\beta_{5} \text { share_super }_{i t}+\beta_{6} \text { rel_price }_{t}+\sum_{h=1}^{H} \beta_{h} s_{h}+a_{i}+u_{i t}
\end{aligned}
$$

where $a_{i}$ is unobserved, time-invariant household specific heterogeneity and $u_{i t}$ is random noise assumed to be $\sim N\left(0, \sigma^{2}\right)$. The remaining variables are described in Table 1 . The model specification (3) is the main model. 
In constructing the variable share_display_label, we assume that each household has only a marginal influence on this average. For robustness, we estimate the same model (equation (3)), but replace share_display_label with numb_display_label to verify whether the results are similar. A discussion of the differences between these results is included in the 'Results' section.

The food categories included in this analysis were selected to cover different types of food where Choiceslabelled products where available. Moreover, both typically healthy and less healthy food categories were included, as well as food categories that are both part of a standard diet and other categories that are more luxurious or convenient types of food. Based on these criteria, the following five main categories were considered: milk, yoghurt, sauces, cereals and fats/oils. Data for other food categories could have been obtained, but for data quality reasons, they were considered less suitable. These five categories are subdivided into eighteen food groups, which are presented in Table 2 in the 'Results' section below. The data are aggregated into either monthly or quarterly volume shares depending on the shelf-life of the products in that food group and, hence, the purchase frequency. This is done mainly to ensure equality between purchase and consumption and to limit the number of zero purchases to a reasonable level. To ensure that the level of aggregation does not drive the results, models for the less frequently purchased food categories, i.e. fats/oils, cereals and sauces, are estimated based on both a monthly and quarterly aggregation level. This does not change the results. The level of aggregation is, likewise, noted in Table 2 . The models we estimate are all based on equation (3), but differ in product specific explanatory variables and whether monthly or quarterly dummies were used to account for seasonality. To take into account the serial correlation induced in the model by unobserved heterogeneity, random-effects Tobit models are estimated using the statistical software package Stata version 14.2.

\section{Results}

A representation of the data is provided in Table 2. To exemplify the interpretation of the table, we discuss ordinary milk in the following. As presented in the second row of Table 2, there were 7216 distinct households observed purchasing ordinary milk during our data period, which in total adds up to 182405 monthly observations. There were 391 distinct products defined based on their EAN-codes, thirty-five of which displayed the Choices label. Of all ordinary milk, $11.2 \%$ (volume share) displayed the Choices label on the packaging (calculated for the period January 2006 to December 2008, i.e. the period when it was possible to obtain the Choices label). Over the entire data period, $14.5 \%$ of the products belonged to the treatment group (i.e. were defined as eligible, share_eligible). The average price for the eligible products was $€ 0.70$ per litre, while products that were not defined as eligible averaged $€ 0.54$ per litre. In $75.5 \%$ of the months, the households purchased only products that were not defined as eligible (share of 0's, last column in Table 2).

\section{The effect of the Choices label on the volume share of eligible products}

Table 3 gives an overview of the effect of displaying the Choices label on the packaging on the volume share of eligible products purchased.* Tables $4-8$ show the average partial effects of displaying the Choices label on the packaging on both the probability of purchasing eligible products, as well as on the expected volume share of eligible products purchased. Furthermore, Tables 4-8 show the partial effects of selected product characteristics and of the relative price of eligible products. The variable of main interest is the share_display_label, the share of products within a specific food group that display the Choices label. To verify the results, we estimate the same model (equation (3)), but replace share_display_label with numb_display_ label, as specified in equation (2b). The average partial effects for the estimation with the number of products that displayed the label are presented in the online supplementary material, Supplemental File B, while parameter estimates for the estimation with share_display_label as the explained variable are shown in Supplemental File C. $\dagger$

Table 3 presents an overview of the estimated treatment effects from the Choices label. The treatment effects are compared between the model specifications with market share of products displaying the label and with number of labelled products as explanatory variable, respectively. We find positive and significant effects for all types of milk and yoghurt. This holds for both treatment measures. In the sauce category, which is considered to consist of mainly convenience products, displaying the label has a positive effect for vinaigrette and mayonnaise (not significant in the model with numbers of products that display the label as explanatory variable), while displaying the label has a negative effect for mayonnaise light. The effect for dressing differs in sign between the two specifications, but is insignificant in the model with the number of products that display the label as explanatory variable. For fats and oils, displaying the label on the packaging has negative, but mostly insignificant effects with the exception of margarine light, for which the effect is significant. Finally,

*Alternative specifications of the model have been tried. We estimated models where the volume shares of specific brands that were eligible for the Choices label out of total volume of this specific type of product were used as the explained variable. This form of specification makes the average treatment effect set-up clearer. However, for most products, the volume share for any one product is very small and the number of 0's and 1's is immense, which implies that the results becomes unreliable.

$\dagger$ The parameter estimates for the sensitivity estimation with numb_display_label are available from the authors upon request 
Table 2 Data statistics, average over the period 2005-2008

\begin{tabular}{|c|c|c|c|c|c|c|c|c|c|c|}
\hline & & \multicolumn{2}{|c|}{ Number } & \multicolumn{2}{|c|}{$\begin{array}{c}\text { Number of } \\
\text { distinct products }\end{array}$} & \multicolumn{2}{|c|}{ Volume share (\%) } & \multicolumn{2}{|c|}{$\begin{array}{c}\text { Price } \\
(€ / \mathrm{kg} \text { or } € / \mathrm{l})\end{array}$} & \multirow[b]{2}{*}{ Share 0's* $(\%$} \\
\hline & & $\mathrm{HH}$ & OBS & Total & Choices & Choicest & Eligible & Eligible & Other & \\
\hline \multirow[t]{3}{*}{ Milk } & Buttermilk & 3967 & 58648 & 82 & 18 & 19.45 & $48 \cdot 4$ & 0.79 & 0.51 & $66 \cdot 3$ \\
\hline & Ordinary milk & 7216 & 182405 & 391 & 35 & $11 \cdot 20$ & 14.5 & 0.70 & 0.54 & $75 \cdot 5$ \\
\hline & Chocolate milk & 4606 & 39063 & 152 & 12 & $9 \cdot 70$ & $13 \cdot 1$ & 0.91 & 0.77 & 84.6 \\
\hline \multirow[t]{4}{*}{ Yoghurt } & Drink-yoghurt & 6093 & 92413 & 410 & 50 & $32 \cdot 3$ & $36 \cdot 9$ & 1.23 & 1.02 & 51.8 \\
\hline & Yoghurt & 7182 & 177936 & 1133 & 51 & $12 \cdot 7$ & $12 \cdot 9$ & $1 \cdot 12$ & 1.08 & $76 \cdot 3$ \\
\hline & Quark & 6209 & 76709 & 346 & 7 & $5 \cdot 33$ & $7 \cdot 8$ & 2.53 & $2 \cdot 10$ & $89 \cdot 2$ \\
\hline & Other dairy & 4130 & 32253 & 154 & 13 & $8 \cdot 0$ & $9 \cdot 3$ & 1.01 & $2 \cdot 16$ & $87 \cdot 8$ \\
\hline \multirow[t]{4}{*}{ Saucesł } & Mayonnaise & 5702 & 32957 & 248 & 21 & $14 \cdot 8$ & 21.5 & $2 \cdot 62$ & 1.85 & 73.9 \\
\hline & Mayonnaise light & 4283 & 21404 & 93 & 28 & $22 \cdot 0$ & $41 \cdot 3$ & 1.78 & $1 \cdot 17$ & $52 \cdot 9$ \\
\hline & Dressing & 3097 & 13350 & 41 & 9 & 9.2 & $22 \cdot 7$ & 1.28 & 1.75 & $76 \cdot 1$ \\
\hline & Vinaigrette & 4910 & 21693 & 425 & 22 & 5.5 & $10 \cdot 8$ & $2 \cdot 10$ & $2 \cdot 67$ & $85 \cdot 9$ \\
\hline \multirow[t]{3}{*}{ Cereals $\ddagger$} & Muesli & 4057 & 20366 & 322 & 1 & 0.8 & $2 \cdot 80$ & 1.00 & $2 \cdot 86$ & $95 \cdot 9$ \\
\hline & Oatmeal & 831 & 2265 & 54 & 1 & 14.1 & $11 \cdot 3$ & 1.32 & $1 \cdot 31$ & $86 \cdot 8$ \\
\hline & Cereal powder & 2526 & 10461 & 17 & 4 & 1.17 & $18 \cdot 2$ & $0 \cdot 81$ & 1.40 & 74.3 \\
\hline \multirow[t]{4}{*}{ Fats/oilsł } & Frying/baking & 5513 & 37410 & 102 & 11 & $12 \cdot 7$ & 18.9 & $3 \cdot 32$ & 2.75 & $75 \cdot 8$ \\
\hline & Oil & 6005 & 30811 & 424 & 46 & $12 \cdot 5$ & $19 \cdot 0$ & $5 \cdot 26$ & $2 \cdot 74$ & $76 \cdot 0$ \\
\hline & Margarine light & 6214 & 48942 & 94 & 22 & $30 \cdot 4$ & 43.5 & $3 \cdot 13$ & 1.48 & $49 \cdot 3$ \\
\hline & Margarine & 6825 & 58836 & 200 & 30 & $18 \cdot 3$ & $23 \cdot 7$ & $2 \cdot 88$ & 1.69 & 64.5 \\
\hline
\end{tabular}

$\mathrm{HH}$, households; OBS, observations.

${ }^{*}$ This is the share of months where zero purchases of eligible products are observed.

†Only averaged over January 2006 to December 2008, i.e. the period where it was possible to get the Choices label.

$\ddagger$ Averaged over quarters rather than months, due to infrequent purchase rates and long shelf-life.

Table 3 Overview of the effects of displaying the Choices label on the volume share of products

\begin{tabular}{|c|c|c|c|}
\hline $\begin{array}{l}\text { Product } \\
\text { category }\end{array}$ & $\begin{array}{l}\text { Product } \\
\text { group }\end{array}$ & $\begin{array}{c}\text { Effect from } \\
\text { share_display_label }\end{array}$ & $\begin{array}{c}\text { Effect from } \\
\text { numb_display_label }\end{array}$ \\
\hline \multirow[t]{3}{*}{ Milk } & $\begin{array}{l}\text { Ordinary } \\
\text { milk }\end{array}$ & + & + \\
\hline & $\begin{array}{l}\text { Chocolate } \\
\text { milk }\end{array}$ & + & + \\
\hline & Butter milk & + & + \\
\hline \multirow[t]{4}{*}{ Yoghurts } & Yoghurt & + & + \\
\hline & $\begin{array}{l}\text { Drink- } \\
\text { yoghurt }\end{array}$ & + & + \\
\hline & Quark & + & + \\
\hline & Other dairy & + & + \\
\hline \multirow[t]{4}{*}{ Sauces } & Dressing & $0($ direction +$)$ & - \\
\hline & Vinaigrette & + & + \\
\hline & Mayonnaise & + & 0 (direction + ) \\
\hline & $\begin{array}{l}\text { Mayonnaise } \\
\text { light }\end{array}$ & - & - \\
\hline \multirow{4}{*}{$\begin{array}{l}\text { Fats and } \\
\text { oils }\end{array}$} & Oil & 0 (direction -) & 0 (direction -) \\
\hline & Margarine & 0 (direction -) & - \\
\hline & $\begin{array}{l}\text { Margarine } \\
\text { light }\end{array}$ & - & - \\
\hline & $\begin{array}{l}\text { Fry bake } \\
\text { products }\end{array}$ & 0 (direction -) & 0 (direction -) \\
\hline \multirow[t]{3}{*}{ Cereals } & Oatmeal & 0 (direction +) & 0 (direction -) \\
\hline & $\begin{array}{l}\text { Cereal } \\
\text { powder }\end{array}$ & 0 (direction -) & - \\
\hline & Muesli & 0 (direction +) & $0($ direction +$)$ \\
\hline
\end{tabular}

+ , positive effect, significant at $5 \%$ level; -, negative effect, significant at $5 \%$ level; 0 , non-significant effect.

for cereals, displaying the label on the packaging has no significant effects.

The partial effects are shown in Tables 4-8. Considering ordinary milk products, the positive effect holds for expected market shares (column 2) as well as the probability of purchasing an eligible product (column 4). For example, if the share of ordinary milk products displaying the Choices label increases by 10 percentage points (pp), the probability of purchasing eligible products will increase by $1.0 \mathrm{pp}$. For butter milk (column 8 ) and chocolate milk (column 12), the increase is 0.5 and $3.3 \mathrm{pp}$, respectively. The expected volume shares of eligible products will increase by $0.9,0.7$ and $11.5 \mathrm{pp}$ for the three food groups (columns 2, 6 and 10), respectively. For drink-yoghurt, ordinary yoghurt, quark and other dairy, the probability of purchasing eligible products (columns 4, 8, 12 and 16 in Table 7) will increase by $0 \cdot 8,3 \cdot 3,5 \cdot 8$ and $5 \cdot 8 \%$, respectively (with a $1.2,2 \cdot 5,14.0$ and $15 \cdot 2 \mathrm{pp}$ in the expected volume shares; columns 2, 6, 10 and 14 in Table 7). In addition to the results regarding the display of the Choices label, we briefly comment on the results for other selected parameters in the following. First, the general pattern is that the larger the share of organic products purchased, the lower the probability of purchasing and the smaller the expected volume share of eligible products. Exceptions from this pattern are ordinary milk and butter milk. Second, the share of products from retailers' own label is negatively correlated with the volume share of eligible products for the majority of the food groups. Third, overall, the volume share purchased in discount stores relative to service and other stores has a negative or insignificant effect on the volume share of eligible products, while for most food groups the opposite correlation holds for the share of products purchased in supermarkets. Fourth, the effect of changing the relative price of eligible products compared with other products is 
Table 4 Partial effects for share of eligible products purchased: milk products

\begin{tabular}{|c|c|c|c|c|c|c|c|c|c|c|c|c|}
\hline \multirow[b]{3}{*}{ (1) } & \multicolumn{4}{|c|}{ Ordinary milk } & \multicolumn{4}{|c|}{ Butter milk } & \multicolumn{4}{|c|}{ Chocolate milk } \\
\hline & \multicolumn{2}{|c|}{ Expected volume } & \multicolumn{2}{|c|}{ Probability } & \multicolumn{2}{|c|}{ Expected volume } & \multicolumn{2}{|c|}{ Probability } & \multicolumn{2}{|c|}{ Expected volume } & \multicolumn{2}{|c|}{ Probability } \\
\hline & $\begin{array}{c}\text { Coef. } \\
\text { (2) }\end{array}$ & $\begin{array}{l}\text { Prob. } \\
\text { (3) }\end{array}$ & $\begin{array}{c}\text { Coef. } \\
\text { (4) }\end{array}$ & $\begin{array}{l}\text { Prob. } \\
\text { (5) }\end{array}$ & $\begin{array}{c}\text { Coef. } \\
(6)\end{array}$ & $\begin{array}{c}\text { Prob. } \\
\text { (7) }\end{array}$ & $\begin{array}{c}\text { Coef. } \\
\text { (8) }\end{array}$ & $\begin{array}{c}\text { Prob. } \\
\text { (9) }\end{array}$ & $\begin{array}{c}\text { Coef. } \\
\text { (10) }\end{array}$ & $\begin{array}{c}\text { Prob. } \\
\text { (11) }\end{array}$ & $\begin{array}{c}\text { Coef. } \\
\text { (12) }\end{array}$ & $\begin{array}{c}\text { Prob. } \\
\text { (13) }\end{array}$ \\
\hline Share_display_label & 0.0883 & 0.0000 & 0.1018 & 0.0000 & & 0.0160 & & 0.0160 & 1.1499 & 0.0000 & 0.3253 & 0.0000 \\
\hline Share_organic & 0.0429 & 0.0000 & 0.0494 & 0.0000 & 0.1793 & 0.0000 & 0.1190 & 0.0000 & $-2 \cdot 4615$ & 0.9790 & -0.6963 & 0.9790 \\
\hline Share_ownlabel & -0.2812 & 0.0000 & -0.3240 & 0.0000 & -0.7059 & 0.0000 & -0.4684 & 0.0000 & -0.5286 & 0.0000 & -0.1495 & 0.0000 \\
\hline Share_discount & -0.0015 & 0.5560 & -0.0017 & 0.5560 & 0.0076 & 0.3380 & 0.0050 & 0.3390 & -0.3195 & 0.0000 & -0.0904 & 0.0000 \\
\hline Share_super & -0.0093 & 0.0000 & -0.0107 & 0.0000 & 0.0504 & 0.0000 & 0.0334 & 0.0000 & -0.0291 & 0.0630 & -0.0082 & 0.0620 \\
\hline Rel_price & -0.0977 & 0.0000 & -0.1125 & 0.0000 & -0.1919 & 0.0000 & -0.1273 & 0.0000 & -0.0335 & 0.7810 & -0.0095 & 0.7810 \\
\hline
\end{tabular}

Note: Conventional, not own label and service stores is base.

(1), ..., (13), column number; coef., coefficient; prob., $P$ value.

Table 5 Partial effects for share of eligible products purchased: cereal products

\begin{tabular}{|c|c|c|c|c|c|c|c|c|c|c|c|c|}
\hline \multirow[b]{3}{*}{ (1) } & \multicolumn{4}{|c|}{ Oatmeal } & \multicolumn{4}{|c|}{ Cereal powder } & \multicolumn{4}{|c|}{ Muesli } \\
\hline & \multicolumn{2}{|c|}{ Expected volume } & \multicolumn{2}{|c|}{ Probability } & \multicolumn{2}{|c|}{ Expected volume } & \multicolumn{2}{|c|}{ Probability } & \multicolumn{2}{|c|}{ Expected volume } & \multicolumn{2}{|c|}{ Probability } \\
\hline & $\begin{array}{c}\text { Coef. } \\
\text { (2) }\end{array}$ & $\begin{array}{l}\text { Prob. } \\
\text { (3) }\end{array}$ & $\begin{array}{c}\text { Coef. } \\
\text { (4) }\end{array}$ & $\begin{array}{l}\text { Prob. } \\
\text { (5) }\end{array}$ & $\begin{array}{c}\text { Coef. } \\
(6)\end{array}$ & $\begin{array}{l}\text { Prob. } \\
\text { (7) }\end{array}$ & $\begin{array}{c}\text { Coef. } \\
\text { (8) }\end{array}$ & $\begin{array}{l}\text { Prob. } \\
\text { (9) }\end{array}$ & $\begin{array}{c}\text { Coef. } \\
\text { (10) }\end{array}$ & $\begin{array}{c}\text { Prob. } \\
\text { (11) }\end{array}$ & $\begin{array}{c}\text { Coef. } \\
\text { (12) }\end{array}$ & $\begin{array}{c}\text { Prob. } \\
\text { (13) }\end{array}$ \\
\hline Share_display_label & 1.0866 & 0.3250 & 0.3065 & 0.3140 & -0.0699 & 0.2530 & -0.0446 & 0.2530 & 0.3963 & 0.2720 & 0.1017 & 0.2710 \\
\hline Share_organic & $-2 \cdot 3124$ & 0.9930 & -0.6523 & 0.9930 & -0.2119 & 0.0000 & -0.1351 & 0.0000 & -0.0989 & 0.0110 & -0.0254 & 0.0110 \\
\hline Share_ownlabel & 1.2879 & 0.0000 & 0.3633 & 0.0000 & $-2 \cdot 3754$ & 0.9860 & -1.5145 & 0.9860 & 0.2874 & 0.0000 & 0.0738 & 0.0000 \\
\hline Share_discount & 0.5705 & 0.0000 & 0.1609 & 0.0000 & -0.1406 & 0.0000 & -0.0897 & 0.0000 & -0.0629 & 0.0000 & -0.0161 & 0.0000 \\
\hline Share super & 0.8506 & 0.0000 & 0.2399 & 0.0000 & 0.0454 & 0.0000 & 0.0289 & 0.0000 & 0.1343 & 0.0000 & 0.0345 & 0.0000 \\
\hline Rel_price & -0.1128 & 0.8610 & -0.0318 & 0.8610 & 0.4594 & 0.0010 & 0.2929 & 0.0010 & -0.1799 & 0.5390 & -0.0462 & 0.5390 \\
\hline
\end{tabular}

Note: Conventional, not own label and service stores is base.

(1), ..., (13), column number; coef., coefficient; prob., $P$ value.

negative for the majority of the food groups. The relative price may capture differences in quality between the eligible and non-eligible products that we do not capture in the variables included in the model, which may explain the few cases of positive relative price effects.

\section{Discussion}

In general, we find that displaying the Choices label increases the volume share of eligible products purchased for dairy products and sauces, i.e. the treatment of displaying the label on the package has a positive effect on the treatment group. For some of the food groups, the partial effect is considerable in size. For example, a 10 pp increase in the market share of products displaying the Choices label will increase the volume share of eligible products purchased for chocolate milk by $11.5 \mathrm{pp}$, for quark by $14.0 \mathrm{pp}$, for vinaigrette by $9.6 \mathrm{pp}$ and for other dairy by $15.2 \mathrm{pp}$. The effects are insignificant for cereals and negative or insignificant for fats and oils. However, these product categories are consumed only moderately, especially fats and oils, which constitute only $1.6 \%$ of the total volume purchased, whereas cereals constitute $14.3 \%{ }^{(37)}$. One possible explanation for the observed differences between the food categories is that consumers use the Choices label less when choosing foods from categories that are perceived as healthy (like most cereals). Also, some of the products might have a specific taste that is correlated with the unhealthiness of the product (like fat in fats and oils), so a light version with less fat does not stimulate people to consume it, even if it displays the label. This explanation may also apply to the negative effect of displaying the label in the mayonnaise light and margarine light groups. The same may also apply to dressing for which the effect of displaying the label is insignificant. We note that our estimations only take into account substitution between unhealthy and healthy products within the group, while the label may also lead to substitution between groups or even between categories, i.e. from margarine to oil. To control for the effects of aggregation and to verify our results, we estimated the same models with all food groups within a category aggregated to one common product, e.g. all purchases of cereals, muesli and cereal powder aggregated to one product called 'cereals' and similarly for the other food categories. The estimation for the milk, yoghurt, cereal and fats and oil categories did not show results different from the group effects. However, for the sauce aggregate, displaying the label had a positive and 
Table 6 Partial effects for share of eligible products purchased: sauce products

\begin{tabular}{|c|c|c|c|c|c|c|c|c|c|c|c|c|c|c|c|c|}
\hline \multirow[b]{3}{*}{ (1) } & \multicolumn{4}{|c|}{ Vinaigrette } & \multicolumn{4}{|c|}{ Dressing } & \multicolumn{4}{|c|}{ Mayonnaise } & \multicolumn{4}{|c|}{ Mayonnaise light } \\
\hline & \multicolumn{2}{|c|}{ Expected volume } & \multicolumn{2}{|c|}{ Probability } & \multicolumn{2}{|c|}{ Expected volume } & \multicolumn{2}{|c|}{ Probability } & \multicolumn{2}{|c|}{ Expected volume } & \multicolumn{2}{|c|}{ Probability } & \multicolumn{2}{|c|}{ Expected volume } & \multicolumn{2}{|c|}{ Probability } \\
\hline & $\begin{array}{l}\text { Coef. } \\
\text { (2) }\end{array}$ & $\begin{array}{l}\text { Prob. } \\
\text { (3) }\end{array}$ & $\begin{array}{l}\text { Coef. } \\
\text { (4) }\end{array}$ & $\begin{array}{l}\text { Prob. } \\
\text { (5) }\end{array}$ & $\begin{array}{c}\text { Coef. } \\
(6)\end{array}$ & $\begin{array}{l}\text { Prob. } \\
\text { (7) }\end{array}$ & $\begin{array}{c}\text { Coef. } \\
\text { (8) }\end{array}$ & $\begin{array}{l}\text { Prob. } \\
\text { (9) }\end{array}$ & $\begin{array}{l}\text { Coef. } \\
\text { (10) }\end{array}$ & $\begin{array}{c}\text { Prob. } \\
\text { (11) }\end{array}$ & $\begin{array}{c}\text { Coef. } \\
\text { (12) }\end{array}$ & $\begin{array}{c}\text { Prob. } \\
\text { (13) }\end{array}$ & $\begin{array}{c}\text { Coef. } \\
\text { (14) }\end{array}$ & $\begin{array}{c}\text { Prob. } \\
\text { (15) }\end{array}$ & $\begin{array}{c}\text { Coef. } \\
\text { (16) }\end{array}$ & $\begin{array}{c}\text { Prob. } \\
\text { (17) }\end{array}$ \\
\hline $\begin{array}{l}\text { Share_display_label } \\
\text { Share_organic }\end{array}$ & $\begin{array}{r}0.9602 \\
-0.4056\end{array}$ & $\begin{array}{l}0.0000 \\
0.2960\end{array}$ & $\begin{array}{r}0.3843 \\
-0.1623\end{array}$ & $\begin{array}{l}0.0000 \\
0.2960\end{array}$ & $\begin{array}{l}0.2257 \\
\text { NA }\end{array}$ & 0.2770 & 0.0569 & 0.277 & $\begin{array}{r}1.3306 \\
-0.9147\end{array}$ & $\begin{array}{l}0.0000 \\
0.0000\end{array}$ & $\begin{array}{r}0.5870 \\
-0.4036\end{array}$ & $\begin{array}{l}0.0000 \\
0.0000\end{array}$ & $\begin{array}{c}-0.5005 \\
\text { NA }\end{array}$ & 0.0000 & $-0 \cdot 1664$ & 0.0000 \\
\hline Share_ownlabel & -0.2428 & 0.0000 & -0.0972 & 0.0000 & 1.6388 & 0.0000 & 0.4135 & 0.000 & -0.3805 & 0.0000 & -0.1679 & 0.0000 & -0.4931 & 0.0000 & -0.1639 & 0.0000 \\
\hline Share_discount & 0.0369 & 0.4120 & 0.0148 & 0.4120 & 1.4888 & 0.0000 & 0.3757 & 0.000 & -0.1427 & 0.0000 & -0.0630 & 0.0000 & -0.4336 & 0.0000 & -0.1442 & 0.0000 \\
\hline Share_super & 0.3388 & 0.0000 & 0.1356 & 0.0000 & 1.6116 & 0.0000 & 0.4067 & 0.000 & 0.0904 & 0.0020 & 0.0399 & 0.0020 & 0.7518 & 0.0000 & 0.2500 & 0.0000 \\
\hline Rel_price & -0.4214 & 0.0620 & -0.1687 & 0.0620 & -1.5084 & 0.0000 & -0.3806 & 0.000 & 0.2504 & 0.0000 & 0.1105 & 0.0000 & -0.2098 & 0.000 & -0.0835 & 0.0000 \\
\hline
\end{tabular}

Note: Conventional, not own label and service stores is base.

(1)..... (17), column number; coef., coefficient; prob., $P$ value; NA, products do not exist in an organic version.

Table 7 Partial effects for share of eligible products purchased: yoghurt products

\begin{tabular}{|c|c|c|c|c|c|c|c|c|c|c|c|c|c|c|c|c|}
\hline \multirow[b]{3}{*}{ (1) } & \multicolumn{4}{|c|}{ Drink-yoghurt } & \multicolumn{4}{|c|}{ Ordinary yoghurt } & \multicolumn{4}{|c|}{ Quark } & \multicolumn{4}{|c|}{ Other dairy } \\
\hline & \multicolumn{2}{|c|}{ Expected volume } & \multicolumn{2}{|c|}{ Probability } & \multicolumn{2}{|c|}{ Expected volume } & \multicolumn{2}{|c|}{ Probability } & \multicolumn{2}{|c|}{ Expected volume } & \multicolumn{2}{|c|}{ Probability } & \multicolumn{2}{|c|}{ Expected volume } & \multicolumn{2}{|c|}{ Probability } \\
\hline & $\begin{array}{l}\text { Coef. } \\
\text { (2) }\end{array}$ & $\begin{array}{l}\text { Prob. } \\
\text { (3) }\end{array}$ & $\begin{array}{l}\text { Coef. } \\
\text { (4) }\end{array}$ & $\begin{array}{l}\text { Prob. } \\
\text { (5) }\end{array}$ & $\begin{array}{l}\text { Coef. } \\
\text { (6) }\end{array}$ & $\begin{array}{l}\text { Prob. } \\
\text { (7) }\end{array}$ & $\begin{array}{l}\text { Coef. } \\
\text { (8) }\end{array}$ & $\begin{array}{l}\text { Prob. } \\
\text { (9) }\end{array}$ & $\begin{array}{c}\text { Coef. } \\
\text { (10) }\end{array}$ & $\begin{array}{c}\text { Prob. } \\
\text { (11) }\end{array}$ & $\begin{array}{c}\text { Coef. } \\
\text { (12) }\end{array}$ & $\begin{array}{c}\text { Prob. } \\
\text { (13) }\end{array}$ & $\begin{array}{c}\text { Coef. } \\
\text { (14) }\end{array}$ & $\begin{array}{c}\text { Prob. } \\
\text { (15) }\end{array}$ & $\begin{array}{c}\text { Coef. } \\
\text { (16) }\end{array}$ & $\begin{array}{c}\text { Prob. } \\
\text { (17) }\end{array}$ \\
\hline Share_display_label & 0.1225 & 0.0000 & 0.0848 & 0.0000 & 0.2494 & 0.0000 & 0.3252 & 0.0000 & 1.3998 & 0.0000 & 0.5755 & 0.0000 & 1.5180 & 0.0000 & 0.5845 & 0.0000 \\
\hline Share_organic & $-1 \cdot 2348$ & 0.0000 & -0.8543 & 0.0000 & -0.0930 & 0.0000 & -0.1212 & 0.0000 & -0.2680 & 0.0000 & -0.1102 & 0.0000 & $-8 \cdot 2770$ & 0.9830 & $-3 \cdot 1872$ & 0.9830 \\
\hline Share_ownlabel & -0.7103 & 0.0000 & -0.4914 & 0.0000 & -0.2273 & 0.0000 & -0.2963 & 0.0000 & 0.1328 & 0.0000 & 0.0546 & 0.0000 & -0.6609 & 0.0000 & -0.2545 & 0.0000 \\
\hline Share_discount & -0.0264 & 0.0000 & -0.0182 & 0.0000 & -0.0077 & 0.0030 & -0.0101 & 0.0030 & -0.3239 & 0.0000 & -0.1332 & 0.0000 & -0.1052 & 0.0000 & -0.0405 & 0.0000 \\
\hline Share_super & 0.0107 & 0.0410 & 0.0074 & 0.0410 & 0.0264 & 0.0000 & 0.0344 & 0.0000 & 0.0874 & 0.0000 & 0.0359 & 0.0000 & -0.0525 & 0.0000 & -0.0202 & 0.0000 \\
\hline Rel_price & -0.0052 & 0.6910 & -0.0036 & 0.6910 & -0.0370 & 0.0120 & -0.0482 & 0.0120 & 0.0374 & 0.3040 & 0.0154 & 0.3040 & -0.6135 & 0.0000 & -0.2362 & 0.0000 \\
\hline
\end{tabular}

Note: Conventional, not own label and service stores is base.

(1), ..., (17), column number; coef., coefficient; prob., $P$ value. 
significant effect, which suggests some intra-category substitution between the various groups in the sauce category, e.g. from mayonnaise light or dressing to vinaigrette.

The negative effect of the share of organic products sold on the volume share of eligible products purchased for most food groups may be explained by the fact that organic producers in the Netherlands mainly promote the healthiness of their products by using the organic label, not the Choices label. Therefore, the number of products with both the organic label and the Choices label is very low, as is the probability of buying these products. Similarly, the share of products from retailers' own label (private label) is negatively correlated with the volume share of eligible products purchased for all milk, yoghurt and fats and oils and most sauces and cereal powder. This may be attributed to the fact that producers of private-label products were slower at adopting the Choices label than the producers of brand products. Finally, the larger the share purchased in discount stores relative to service stores, the smaller the volume share of eligible products, while the opposite correlation holds for supermarkets for the majority of the food groups. The two biggest discount chains in the Netherlands did not join the initiative in the period of the present study. In addition, these discount shops have a much higher percentage of private-label products. Service stores, on the other hand, are usually smaller and, hence, have less variety than supermarkets, which might explain the positive effect of the volume share of products purchased in supermarkets relative to service stores on the volume share of eligible products purchased. Overall, for the majority of food groups, we find that displaying the Choices label stimulates the purchase of eligible products, although the effect differs between food categories and between food groups within the categories. Generally, the Choices label has an effect in food groups where the label can be used as a real choice (i.e. in groups that consist of a mix of healthy and unhealthy products), while it is not useful for very unhealthy food groups (e.g. for food groups from the fats and oils category) or for food groups that are perceived as generically healthy (e.g. from the cereals category). This is in line with the finding that the label is more acceptable for products that are advised to be consumed regularly as part of a healthy diet, such as milk products or bread, compared with more indulgent or convenience food products such as sauces or soups (Dutch Choices Foundation, personal communication).

\section{Strength and limitations of the study}

The strength of the current study is that we consider the effect of displaying a FoP label on household purchases of food in a real market situation. In contrast, the limitation of this type of approach is that purchase data include a considerable amount of noise, which we are unable to control for. This type of noise encompasses, for example, the fact that there may be differences in certain quality aspects that 
the consumers observe, but these may not be reflected in the data within each food group (e.g. for cereals this might be whether the product contains fruit or not). This quality difference might be reflected by the differences between the prices of eligible and non-eligible products. However, we consider numerous different food groups for a considerable number of consumers, while we are also able to consider the purchases of the foods both before and after the introduction of the label. We are, therefore, confident that the results provide a valid picture of the effect of introducing FoP labels on purchasing behaviour. Despite the potential endogeneity of our main variable of interest (i.e. the market share of products displaying the label on the package), we consider the estimations to be reliable as each household makes only a minimal contribution to the average, and as we consider the volume share of eligible products both before and after the introduction of the labelling regime. Furthermore, we replicate the estimations with the number of products that display the label as the variable of interest and obtain similar results for all food groups except oatmeal and dressing, both of which show insignificant effects. This further strengthens the conclusions.

The conclusion that the increased presence of nutrition labels on the packaging has a positive effect on the volume share of eligible products purchased is relatively robust across food groups and specifications. However, 'eligible' products are here defined as products that, at some point in the period of the data, obtained the label. We note that other products may also have fulfilled the requirements while not displaying the label on the packaging. Finally, the data include information about purchases, not the real consumption of the individuals within these households. The models predict only the change in the relative consumption of foods, but it would be interesting to study the effect of the label on health parameters in the observed individuals (e.g. sodium intake, blood pressure, blood lipids).

The overall results suggest that displaying the Choices label has a positive effect on the volume share of eligible products purchased, after controlling for product specific characteristics and household characteristics. These findings are based on panel data, including time periods prior to and following the introduction of the Choices nutrition label in the Netherlands, leading to an average treatment effect set-up, lending support to a causal interpretation. Moreover, the findings hold for two different measures of the availability of nutrition-labelled products: the share of eligible products that actually display the label based on either the market share or the number of products. The robustness of the findings across these two measures strengthens the reliability of the results. While the general results from the availability of nutrition-labelled products are positive, there are variations between the eighteen food groups. For the dairy products and for the sauces (e.g. vinaigrette and mayonnaise), the effect is positive and significant and of a considerable size. Meanwhile, the food categories cereals and fats and oils reveal mainly insignificant or negative effects across food groups and across measures of the availability of nutrition labels. These differences suggest that the Choices label has a minimal or no effect in food categories that are considered less healthy (e.g. fats and oil) and in food categories where the perception is that this type of food is generically healthy (cereals). However, the Choices label will be a good guide in food groups and food categories that consist of both healthy and unhealthy products and constitute a large share of the diet.

\section{Conclusion}

Most studies available regarding the use of FoP nutrition labels are based on hypothetical survey data or data revealed from experiments. While contributing rich information about attitudes, knowledge and interest, these methods do not reveal how this translates into purchases on the market. A recent study shows that there is a positive correlation between self-reported preferences for a Danish nutrition label (Keyhole) and actual purchases of labelled products, but the correlation holds only for those with strong positive preferences $^{(38)}$. These results suggest that it is important to analyse actual purchase behaviour when evaluating the usefulness of FoP nutrition labels. The present study contributes an analysis based on consumer panel purchase data. We conclude that displaying the Choices label makes consumers purchase relatively more of the group of products that fulfil the healthlabel requirements. However, as we consider relative consumption, we are only able to predict the effects of the label on dietary health by assuming that the total consumption remains constant. Previous research shows that when people who consume an average Dutch daily meal switch from regular products to products that comply with the Choices label, while keeping total consumption constant, their daily intakes of sodium, SFA, sugar, energy and fibre improve towards the recommended amounts ${ }^{(39,40)}$. Combining this result with our results suggests that displaying the label will enable consumers to identify (and choose) healthier products, thereby directing them towards a healthier diet. Furthermore, because of the regular evaluation of and improvements made to the nutritional criteria with which products have to comply in order to display the label, it might be expected that the introduction of the label will slowly improve the composition of products on the market ${ }^{(39-42)}$ and improve the average daily intake in the Netherlands even when no other changes in dietary pattern occur.

\section{Acknowledgments}

Financial support: This work was partly supported by CLYMBOL ('Role of health-related CLaims and sYMBOLs in consumer behaviour') of the European Union's Seventh Framework Programme for research, technological 
development and demonstration (under grant agreement no. 311963). The funder had no role in the design, analysis or writing of this article. Conflict of interest: The authors have no conflicts of interest. Authorship: S.S. made the estimations. All three authors have contributed equally in the writing of this article. Ethics of human subject participation: This study was conducted according to the guidelines laid down in the Declaration of Helsinki and all procedures followed the standards as laid out by the Ethical Committee at the University of Copenhagen, Faculty of Science. No consent from the participating subjects was necessary.

\section{Supplementary material}

To view supplementary material for this article, please visit https://doi.org/10.1017/S1368980019001423

\section{References}

1. World Health Organization (2014) Cardiovascular diseases (CVDs). http://www.who.int/mediacentre/factsheets/fs317/ en/index.html (accessed March 2018).

2. Lim SS, Vos T, Flaxman, AD et al. (2013) A comparative risk assessment of burden of disease and injury attributable to 67 risk factors and risk factor clusters in 21 regions, 1990-2010: a systematic analysis for the Global Burden of Disease Study 2010. Lancet 380, 2224-2260.

3. The Lancet (2018) GBD 2017: a fragile world. Lancet 392, 1683.

4. Candari CJ, Cylus J \& Nolte E (2017) Assessing the Economic Costs of Unhealthy Diets and Low Physical Activity: An Evidence Review and Proposed Framework. Health Policy Series no. 47. Copenhagen: WHO Regional Office for Europe.

5. World Health Organization (2011) Prevention and control of NCDs: priorities for investment. In First Global Ministerial Conference on Healthy Lifestyles and Noncommunicable Disease Control. Moscow: WHO.

6. Genannt Bonsmann SS, Celemín LF, Larrañaga A et al (2010) Penetration of nutrition information on food labels across the EU-27 plus Turkey. Eur J Clin Nutr 64, 1379-1385.

7. European Food Information Council (2015) Global Update on Nutrition Labelling. Brussels: European Food Information Council.

8. Hieke S \& Harris JL (2016) Nutrition information and front-ofpack labelling: issues in effectiveness. Public Health Nutr 19 , 2103-2105.

9. Abaluck J (2011) What Would We Eat if We Knew More: The Implications of a Large-Scale Change in Nutrition Labeling. Massachusetts Institute of Technology Working Paper. Cambridge, MA: MIT.

10. Variyam JN (2008) Do nutrition labels improve dietary outcomes? Health Econ 17, 695-708.

11. Patterson M, Bhargava S \& Loewenstein G (2017) An unhealthy attitude? New insight into the modest effects of the NLEA. J Behav Econ Policy 1, 15-26.

12. Cowburn G \& Stockley L (2005) Consumer understanding and use of nutrition labelling: a systematic review. Public Health Nutr 8, 21-28.

13. Grunert K \& Wills J (2007). A review of European research on consumer response to nutrition information on food labels. J Public Health 15, 385-399.

14. Campos S, Doxey J \& Hammond D (2011) Nutrition labels on pre-packaged foods: a systematic review. Public Health Nutr 14, 1496-1506.
15. Kanter R, Vanderlee L \& Vandevijvere S (2018) Frontof-package nutrition labelling policy: global progress and future directions. Public Health Nutr 21, 1399-1408.

16. Vyth EL, Steenhuis IH, Brandt HE et al. (2012) Methodological quality of front-of-pack labeling studies: a review plus identification of research challenges. Nutr Rev 70, 709-720.

17. Volkova E \& Mhurchu CN (2015) The influence of nutrition labeling and point-of-purchase information on food behaviours. Obes Rev Rep 4, 19-29.

18. Julia C \& Hercberg S (2017) Development of a new frontof-pack nutrition label in France: the five-colour Nutri-Score. Public Health Panorama 3, 712-725.

19. Thomson RK, McLean RM, Ning SX et al. (2016) Tick frontof-pack label has a positive nutritional impact on foods sold in New Zealand. Public Health Nutr 19, 2949-2958.

20. Freire WB, Waters WF, Rivas-Mariño G et al. (2017) A qualitative study of consumer perceptions and use of traffic light food labelling in Ecuador. Public Health Nutr 20, 805-813.

21. Sydanmerkki (2018) Heart Symbol. https://www. sydanmerkki.fi/en (accessed March 2018).

22. Vyth EL, Steenhuis IH, Mallant SF et al. (2009) A front-of-pack nutrition logo: a quantitative and qualitative process evaluation in the Netherlands. J Health Commun 14, 631-645.

23. Lahti-Koski M, Helakorpi S, Olli M et al. (2012) Awareness and use of the Heart Symbol by Finnish consumers. Public Health Nutr 15, 476-482.

24. Feunekes GIJ, Gortemaker IA, Willems AA et al. (2008) Frontof-pack nutrition labelling: testing effectiveness of different nutrition labelling formats front-of-pack in four European countries. Appetite 50, 57-70.

25. Arrúa A, Machín L, Curutchet MR et al. (2017) Warnings as a directive front-of-pack nutrition labelling scheme: comparison with the Guideline Daily Amount and traffic-light systems. Public Health Nutr 20, 2308-2317.

26. Cecchini $M \&$ Warin $L$ (2016) Impact of food labelling systems on food choices and eating behaviours: a systematic review and meta-analysis of randomized studies. Obes Rev 17, 201-210.

27. Sutherland LA, Kaley LA \& Fischer L (2010) Guiding Stars: the effect of a nutrition navigation program on consumer purchases at the supermarket. Am J Clin Nutr 91, issue 4, 1090S-1094S.

28. Cawley J, Sweeney MJ, Sobal J et al. (2015) The impact of a supermarket nutrition rating system on purchases of nutritious and less nutritious foods. Public Health Nutr 18, 8-14.

29. Boztuğ Y, Juhl HJ, Elshiewy O et al. (2015) Consumer response to monochrome Guideline Daily Amount nutrition labels. Food Policy 53, 1-8.

30. Sacks G, Rayner M \& Swinburn B (2009) Impact of frontof-pack 'traffic-light' nutrition labelling on consumer food purchases in the UK. Health Promot Int 24, 344-352.

31. Lachat C \& Tseng M (2013) Editorial: a wake-up call for nutrition labelling. Public Health Nutr 16, 381-382.

32. Hamlin RP, McNeill LS \& Moore V (2015) The impact of front-of-pack nutrition labels on consumer product evaluation and choice: an experimental study. Public Health Nutr 18, 2126-2134.

33. Smed S, Edenbrandt AK, Koch-Hansen P et al. (2017) Who is the purchaser of nutrition-labelled products? Br Food J 119, 1934-1952.

34. Edenbrandt AK, Smed S \& Jansen L (2017) A hedonic analysis of nutrition labels across product types and countries. Eur Rev Agric Econ 45, 101-120.

35. Dötsch-Klerk M \& Jansen L (2008) The Choices programme: a simple, front-of-pack stamp making healthy choices easy. Asia Pac J Clin Nutr 17, 383-386.

36. Tobin J (1958) Estimation of relationships for limited dependent variables. Econometrica 26, 24-36.

37. Van Rossum CTM, Buurma-Rethans EJM, Vennemann FBC et al. (2016) The Diet of the Dutch: Results of the First Two Years of the Dutch National Food Consumption Survey 20122016. RIVM Letter Report no. 2016-0082. Bilthoven: RIVM. 
38. Edenbrandt AK \& Smed S (2018) Exploring the correlation between self-reported preferences and actual purchases of nutrition labeled products. Food Policy 77, 71-80.

39. Roodenburg AJC, Temme EHM, Davies OH et al. (2009) Potential impact of the Choices Programme on nutrient intakes in the Dutch population. Nutr Bull 34, 318-323.

40. Roodenburg AJ, Schlatmann A, Dotsch-Klerk M et al. (2011) Potential effects of nutrient profiles on nutrient intakes in the
Netherlands, Greece, Spain, USA, Israel, China and SouthAfrica. PLoS One 6, e14721.

41. Jansen L \& Roodenburg AJ (2016) The use of food composition data in the Choices International Programme. Food Chem 193, 196-202.

42. Vyth EL, Steenhuis IH, Roodenburg AJ et al. (2010) Front-of-pack nutrition label stimulates healthier product development: a quantitative analysis. Int J Behav Nutr Phys Act 7, 65. 